\title{
Acute Exacerbation of Cough as a Precipitating Cause of Hypoxia in COVID-19 Patients
}

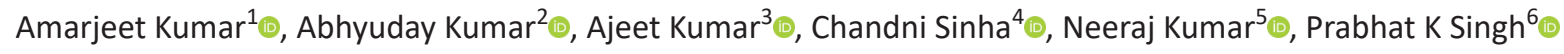

Keywords: Cough, COVID-19, Hypoxemia.

Indian Journal of Critical Care Medicine (2021): 10.5005/jp-journals-10071-24006

Dry Cough is one of the most common initial symptoms of coronavirus disease-2019 (COVID-19), reported in about 60-70\% of symptomatic patients. ${ }^{1}$ Cough can persist for weeks or months following severe acute respiratory syndrome coronavirus 2 (SARSCoV-2) infections. Point of consideration for COVID-19 associated cough includes cough frequency, severity, urge to cough, hypersensitivity, or cough suppressibility. Post-COVID chronic cough might be due to pathological or structural causes, such as fibrosis of lung parenchyma ${ }^{2}$ or damage to the airways caused by either SARS-CoV-2 or the treatment provided in critical care. Lung fibrosis could increase cough reflex sensitivity in response to mechanical stimulation of the chest wall as reported in patients with idiopathic pulmonary fibrosis. ${ }^{3}$ As per our clinical experience, we have detected several factors in the intensive care unit, which precipitated cough in COVID-19 patients. These factors include defecation, micturition in self-voiding patients, posture change, and airway stimulation procedure. The possible mechanisms of cough following COVID-19 infection are stimulation of vagal sensory nerve via several pathways, including neuroinflammatory, neurotropism, and neuroimmunomodulation. ${ }^{4}$ By understanding the path of COVID-19 induced cough, we can combat the cough reflexes by blocking the above pathway at multiple levels. We propose that it is essential to consider cough as a target of intervention in the management of COVID-19 because we detected oxygen desaturation immediately following vigorously coughing COVID-19 patients and oxygen desaturation, which was improved with time when cough exacerbation subside. The possible mechanisms of oxygen desaturation in vigorously coughing patients include a decrease in functional residual capacity, compression of pulmonary capillaries due to increased intrathoracic pressure, which results in poor gaseous exchange, reduced oxygen concentration in conducting airway as a washout effect of forced expiration, and misplacement of oxygen therapy device may also result in the increased air entrainment. The search for different therapeutic strategies to combat COVID-19 is going on and is in different phases of completion. We advocate constant vigilance over the precipitating factors, increased oxygen fraction at the time of cough exacerbation, and a multimodal approach of cough management in COVID-19 patients. Because of the variable and episodic nature of acute viral cough, little firm evidence has been obtained in clinical studies. Cough challenge methodologies have, however, shown suppression of the cough reflex and active agents including dextromethorphan, menthol, sedative antihistamines, codeine, or pholcodine. ${ }^{5}$ Dextromethorphan has a dose response, and maximum cough reflex suppression occurs at $60 \mathrm{mg}$ and can be prolonged. ${ }^{5}$ Menthol by inhalation suppresses the cough reflex and
1,5Department of Trauma and Emergency, All India Institute of Medical Sciences, Patna, Bihar, India

${ }^{2-4}$ Department of Anaesthesiology, All India Institute of Medical Sciences, Patna, Bihar, India

${ }^{6}$ Director, All India Institute of Medical Sciences, Patna, Bihar, India

Corresponding Author: Amarjeet Kumar, Department of Trauma and Emergency, All India Institute of Medical Sciences, Patna, Bihar, India, Phone: +91 09570890646, e-mail: amarjeetdmch@ gmail.com

How to cite this article: Kumar A, Kumar A, Kumar A, Sinha C, Kumar N, Singh PK. Acute Exacerbation of Cough as a Precipitating Cause of Hypoxia in COVID-19 Patients. Indian J Crit Care Med 2021;25(11): 1324-1325.

Source of support: Nil

Conflict of interest: None

may be prescribed as menthol crystals or in the form of proprietary capsules. ${ }^{5}$ Side effects like drowsiness should be kept in mild while prescribing antihistaminic. Several neuromodulators, such as gabapentin or opioids (codeine), might be considered for acute and chronic COVID-19 cough. However, opiate antitussives have a significant adverse side effect profile and are not recommended. ${ }^{5}$ We also advocate proper sedation to suppress the cough in a mechanically ventilated patient and use potent antitussive agents, like dextromethorphan at fixed-dose intervals, and antihistaminic drugs, like levocetirizine, demulcent agents, and mast cell stabilizer.

\section{OrCID}

Amarjeet Kumar (๑ https://orcid.org/0000-0002-4272-5750 Abhyuday Kumar (1) https://orcid.org/0000-0002-9247-6713 Ajeet Kumar (ㅇ https://orcid.org/0000-0002-1464-6684 Chandni Sinha (1) https://orcid.org/0000-0002-4107-2671 Neeraj Kumar $\odot$ https://orcid.org/0000-0002-9161-7000 Prabhat K Singh (1) https://orcid.org/0000-0003-1888-4679

\section{References}

1. Guan WJ, Ni ZY, Hu Y, Liang WH, Ou CQ, He JX, et al. Clinical characteristics of coronavirus disease 2019 in China. N Engl J Med 2020;382:1708-1720. DOI: 10.1056/NEJMoa2002032.

2. Ojha V, Mani A, Pandey NN, Sharma S, Kumar S. CT in coronavirus disease 2019 (COVID-19): a systematic review of chest CT findings in 4410 adult patients. Eur Radiol 2020;30(11):6129-6138. DOI: 10.1007/ s00330-020-06975-7.

(c) The Author(s). 2021 Open Access This article is distributed under the terms of the Creative Commons Attribution 4.0 International License (https://creativecommons. org/licenses/by-nc/4.0/), which permits unrestricted use, distribution, and non-commercial reproduction in any medium, provided you give appropriate credit to the original author(s) and the source, provide a link to the Creative Commons license, and indicate if changes were made. The Creative Commons Public Domain Dedication waiver (http://creativecommons.org/publicdomain/zero/1.0/) applies to the data made available in this article, unless otherwise stated. 
3. Jones RM, Hilldrup S, Hope-Gill BD, Eccles R, Harrison NK. Mechanical induction of cough in idiopathic pulmonary fibrosis. Cough 2011;7:2. DOI: 10.1186/1745-9974-7-2.

4. Song WJ, Hui CKM, Hull JH, Birring SS, McGarvey L, Mazzone SB, et al. Confronting COVID-19 associated cough and the post-COVID syndrome: role of viral neurotropism, neuroinflammation, and neuroimmune responses. Lancet 2021;9(5):533-544. DOI: 10.1016/ S2213-2600(21)00125-9.

5. Morice AH, McGarvey L, Pavord I; British Thoracic Society Cough Guideline Group. Recommendations for the management of cough in adults. Thorax 2006;61(Suppl. 1):i1-i24. DOI: 10.1136/ thx.2006.065144. 